Journal of Energy and
Environmental Sustainability
Journal homepage : www.jees.in

\title{
Development of a Two-stage Impaction Based Bioaerosol-cum-particulate Matter Sampler and its Use for Ambient Aerosol Profile
}

\author{
Amit Singh Chauhan ${ }^{1}$, Tarun Gupta ${ }^{1,2^{*}}$ \\ ${ }^{1}$ Department of Civil Engineering, Indian Institute of Technology Kanpur, Kanpur 208016, India \\ ${ }^{2}$ Atmospheric Particle Technology Laboratory, Centre for Environment Science and Engineering, Indian Institute of Technology Kanpur, Kanpur 208016, India
}

\section{A R T I C L E I N F O}

Received : 08 February 2017

Revised : 07 April 2017

Accepted : 15 May 2017

Keywords:

Air sampling device, Impactor,

Bioaerosols, Particulate matter

\begin{abstract}
A B S T R A C T
Air contains a mixture of various biological and non-biological components. During breathing, human body does not segregate between these components. Studies have provided sufficient proof about the deteriorating effects of degrading air quality on human health. The deterioration in ambient air quality and the emergence of new pollutants in developing countries is also giving rise to the requirement of simple, customized and economical air sampling devices. Relatively simple design, and low cost as compared to real time optical instruments have led to the development of various kinds of impactors. The present study presents a low volume $(\mathrm{Q}=12 \mathrm{LPM})$, two stage $\left(\mathrm{PM}_{10}\right.$ and $\left.\mathrm{PM}_{0.6}\right)$, impaction based device that can be used for bioaerosol and particulate matter sampling. The device is fabricated of brass and chrome plating is done over it. This device eliminates the need for two different sampling devices to be bought for bioaerosol and particulate matter sampling separately, which is of huge economical advantage for developing nations. Developed device is tested in laboratory conditions and field conditions as well. Laboratory testing was carried out for parametric characterization and optimization of the device. Yearlong sampling for PM and bioaerosols as Gram positive bacteria, Gram negative bacteria and fungi was carried out within the IIT Kanpur campus and the results were observed in reference to similar studies in the region. For the first time, yearlong bioaerosol inventory was generated for the IIT Kanpur campus.
\end{abstract}

C) 2017 ISEES, All rights reserved

\section{Introduction}

Deterioration in air quality and its effects on human health are one of the main concerns of the present time. Poor ambient air quality results in the degradation of health and is significantly related to increase in mortality around the globe (Brunekreef and Holgate, 2002; Evans et al., 1984; Hall, 1996; Kampa and Castanas, 2008; Özkaynak and Thurston, 1987). Traditionally, air quality parameters include the gaseous contents, heavy metals, persistent organic pollutants and particulate matter present in the ambient air (Kampa and Castanas, 2008). The air human breath-in is a mixture of various pollutants, gases and several other species. The dose and duration of various pollutants present in inhaled air may vary substantially. This exposure may result in breathing discomfort, various respiratory disorders and other related health issues. The problems due to air pollution may range from allergies, chronic discomfort, disabilities, and even cancerous end. (Kampa and Castanas, 2008). Air pollution affects not only respiratory system but it may also lead to problems in cardiovascular, digestive or urinary system (Järup, 2003; Kuo et al., 2006; Nawrot et al., 2006; Riediker et al., 2004; Vermylen et al., 2005). Traditional air quality measurement relies more on sampling of respirable suspended particulate matters and compositions of these in terms of heavy metals, ions, carbon contents and related parameters. However, fine particles are thought to be more toxic to human beings than comparatively coarse particles due to their higher surface area per unit mass (Harrison and Yin, 2000; Kumar and Gupta, 2015). Further, fine particulate matters can penetrate deep into the human body as compared to coarse particulate matters. Particulate matter of aerodynamic diameter less than $0.6 \mu \mathrm{m}$ may penetrate deep into alveolar region. Sub $\mathrm{PM}_{06}$ particles can enter deeper into the body by diffusion into blood. This study focuses on the fact that the air we breathed in contains a mixture of gases, organic species, adsorbed transition metals and bioaerosols present in the form of particulate matter. The traditional parameters of PM measurement lack measurement of bioaerosols. The term bioaerosol is derived from two words biological and aerosols (Nazaroff, 2016). Thus, bioaerosols may be defined as aerosols with biological origin. They include microorganisms like bacteria, fungi, protozoa or viruses. Bioaerosol may be cultivable, non-cultivable, living or dead. Bioaerosols may also include by-products of living beings like allergens and endotoxins etc. (Cox and Wathes 1995). They may be plant products like pollens, plant debris or fragments from avian or mammalian bodies (Macher and Macher, 1997).

Bioaerosols are responsible for various diseases like aspergillosis, pneumonia, severe acute respiratory syndrome (SARS), and whooping cough etc. (Castellani Pastoris et al., 1997; Fernandez, 2012). They may spread by voluntary activities like aeration of contaminated water or by involuntary processes like sneezing, wheezing, coughing etc. If a bioaerosol is a pathogenic microorganism it can lead to death of the exposed organism and if it contain toxins like aflatoxin it may lead to cancer in the exposed individual (Douwes, 2003). Many qualitative as well as quantitative studies have reported about bioaerosols and their effects in the different occupational and indoor environments. Bioaerosol itself is a subset of the aerosol. Therefore, inhalation path and settling of bioaerosols into the human respiratory tract depends on their size.

\footnotetext{
* Corresponding Author: tarun@iitk.ac.in
} 
Thus, there is a need to study the concentrations and composition of both fine particulate matter and bioaerosols present in the ambient air. This needs an efficient low cost air-sampling device that can be used to collect both fine particulate matter as well as bioaerosols present in the ambient air. Relatively simple design, and low cost as compared to real time optical instruments have led to the development of various kinds of impactors. The deterioration in ambient air quality and the emergence of new pollutants in developing countries is also giving rise to the requirement of customized impactors (Marple, 2004; Singh et al., 2010).

This study was carried out with a goal to develop a two-stage impaction based air sampling device that can be used for both PM sampling as well as bioaerosol sampling. Stage I of the device has cut off diameter of 10 $\mu \mathrm{m}$ and stage II has cut off diameter of $0.6 \mu \mathrm{m}$. The device developed during the study was tested rigorously under laboratory and field conditions. Device was tested using Teflon filter paper for $\mathrm{PM}_{06}$ and $\mathrm{PM}_{10}$ under laboratory conditions. $\mathrm{PM}_{06}$ sampling was also done in the field conditions using the device. Along with this, the device was tested for bioaerosol sampling using different types of agar media as per the objective. Different agar media were used as impaction substrate during the laboratory testing as well as field sampling using this air sampling device. During the study nutrient agar, Mac Conkey agar, Mannitol salt agar and Sabouraud Dextrose Agar with Chloramphenicol were used for collecting bioaerosols. All the agar media were purchased from Himedia Labs.

\section{Development of two-stage air sampling device}

\subsection{Design of an impactor}

An impactor is a simple device through which air passes around the impaction plate such that a sharp change in the trajectory of airflow around it leads to impaction of the higher inertia particles on the impaction plate. Finer particles with less inertia follow the path of sharply bending air, streamlines downstream and eventually get collected on the backup filter. Design equations for inertial impactors have been worked out of the empirical solutions of Naviers-Stokes equations for various air flow conditions around the different forms of impaction plates (Marple and Willeke, 1976; Mcfarland et al., 1978).

Dimensionless Stoke's number is used to calculate the cut point of the round nozzle for impactor.

The Stoke's number is defined as:

$$
S t k=\frac{\rho_{\mathrm{p}} d_{p}^{2} U C_{c}}{9 \eta D_{n}}
$$

Where $\rho_{\mathrm{p}}$ is the particle density $\left(\mathrm{kg} / \mathrm{m}_{3}\right)$, dp stands for diameter of the particle $(\mu \mathrm{m}), \mathrm{U}$ stands for the air jet velocity through the impactor nozzle $(\mathrm{m} / \mathrm{s})$, Cc is Cunningham slip correction factor, $\eta$ is the dynamic viscosity of air (Pa.s) and $\mathrm{D}_{\mathrm{n}}$ is the diameter of the round nozzle in the nozzle plate (Baron and Willeke, 2001).

Cunningham slip correction factor is calculated by the following equation:

$$
C_{c}=1+\frac{1}{\mathrm{P} d_{p}}\left[15.60+7.00 \exp \left\{-0.059 \mathrm{P} d_{p}\right\}\right]
$$

Here, $\mathrm{P}$ is the absolute pressure above the impaction nozzle (Baron and Willeke, 2001).

Numerical analysis of Navier-Stokes equation gives critical design parameters for designing of the round nozzle impactors (Marple and Liu, 1974).Theoretical cut point for collecting particles with $50 \%$ efficiency can be calculated using equation 1 for $\sqrt{S t k_{50}}=0.5$ for the desired flow rate through the specified nozzle diameter.

Equations used for calculating the theoretical $\mathrm{d}_{50}$ and Reynold's number are (Hinds, 1982):

$$
\begin{gathered}
d_{50} \sqrt{C_{c}}=\sqrt{\frac{9 \pi \eta \mathrm{D}_{n}^{3}\left(S t k_{50}\right)}{4 \rho_{\mathrm{p}} Q}} \\
R e=\frac{\rho_{\text {air } U D_{n}}}{\eta}
\end{gathered}
$$

Where $\rho$ air is the density of air in $\mathrm{g} / \mathrm{m}^{3}$

$d_{50} \quad$ particle diameter for $50 \%$ collection efficiency

Q flow rate in $\mathrm{m}^{3} / \mathrm{s}$

Five important concerns for designing an impaction plate and choosing the impaction substrate for a bioaerosol sampler are:

i. Particle bounce-off from the impaction substrate.

ii. Overloading of bioaerosols on the impaction substrate.

iii. Losses of bioaerosols in the flow path within the instrument.

iv. Viability and cultivability of sampled microorganisms and

v. Stability of impaction media during sampling.
The impactor presented in this study has been tested using a thick $(3.5 \mathrm{~mm})$ and smooth coating of high vacuum silicone grease as well as different types of culture media. The culture media is used as impaction substrate for capturing and also for cultivating different microorganisms (Demokritou et. al., 2001; Kumar \& Gupta, 2015).

Equations 1 to 4 were used for designing the round impactor nozzles for $\mathrm{PM}_{10}$ and $\mathrm{PM}_{0.6}$ stages. Stable flow of polydisperse talcum powder aerosols was generated and maintained with the help of a dry aerosol generator working in the form of a venturi (aspirator, Bernouli's principle) (Gupta et. al., 2011). An Aerodynamic Particle Sizer (APS, Model 3021, TSI Inc.), which is based on the time-of-flight principle was used for characterizing the impactor nozzles as per the protocols well established by previous researchers (Demokritou et. al., 2002; Gupta et. al. 2004; Gupta et al., 2011). Aerosol Particle Sizer was used due to its advantage of directly giving the aerodynamic diameter. Thus, the variation in the density of the talcum powder can be ignored. For each stage, several parametric experiments were done to assess the best flow rate at desired cut off point for the respective stages.

\subsubsection{Laboratory performance evaluation of the designed two stage impactor based sampler}

Impactor nozzles for each of the two stages were tested at different flow rates ranging from 7.5 (litres per minute) LPM to $15 \mathrm{LPM}$. Identical, isokinetic sampling probes were used to sample the particles for five minutes from upstream of the impaction stage and alternatively with five minute sampling from down-stream of the respective stage (figure 1). Each experiment continued with at least four such cycles for each stage. The efficiency of each stage was calculated by comparing the measured particle concentrations at up-stream and down-stream of the respective stage.

The impaction plate in each stage was characterized by using high vacuum silicone grease as well as alternatively using different types of agar media (Nutrient agar, Sabouraud Dextrose Agar with Chloramphenicol, MacConkey agar, Mannitol salt agar). The selected agar media were to be used for bioaerosol sampling experiments.

\subsubsection{Optimization of sampling duration for various substrates used for bioaerosol sampling using the developed air sampling device}

Experiments were carried out to optimize the sampling duration on different substrate that is media in the Air Sampling Device. Sampling was carried out on each of these selected media for 1, 2, 3, 5, 7 and 10 minutes respectively in different sets of experiments. Each experiment was repeated at least 7 times for each media and selected time duration. After sampling, the plates were incubated as per the protocol described in section 3.3. After incubation, the number of colony forming units per cubic meter of the sampled air was calculated for each sample.

\section{Field performance evaluation of the sampler}

\subsection{Study area}

Field performance evaluation was carried out inside the main campus of Indian Institute of Technology, Kanpur (IIT Kanpur or IITK). The IIT Kanpur $\left(26.4^{\circ} \mathrm{N}, 80.2^{\circ} \mathrm{E}\right)$ is a residential academic campus located $15 \mathrm{~km}$ north of the industrial town Kanpur. Kanpur is a major industrial hub in the Indo-Gangetic region. Kanpur city is $142 \mathrm{~m}$ above the mean sea level. The Indo-Gangetic region is one of the most polluted regions in the world. The region has high air pollution especially high particulate matter concentrations (Tripathi et al., 2006). Aerosol load in the region is contributed by not only the anthropogenic sources but also natural sources such as dust. Dust storms are quite prevalent in the region, especially during summers (Ghosh et al., 2014).

The study site is located at a distance of $1.5 \mathrm{~km}$ from a national highway (N.H. 91). IIT Kanpur campus is at the upwind direction of the city and has no major emission source nearby (Sharma and Maloo, 2005). In general, outdoor environment at IIT Kanpur has rich and flourishing vegetation in the form of trees, plants and grasses.

The climate of Kanpur can be divided into five distinctly marked seasons. They are pre-summer (March to April), summer (May to June), monsoon (July to August), post monsoon (September to October) and winter (November to February). The average temperature in Kanpur varies from nearly $8{ }^{\circ} \mathrm{C}$ in winter to $\sim 40{ }^{\circ} \mathrm{C}$ in summer. It may dip to below zero degrees Celsius during peak of winter. In summer, this may elevate to even greater than $45{ }^{\circ} \mathrm{C}$ on several days. Relative humidity at Kanpur also varies from $<40 \%$ to $>80 \%$ on several days. This results in two extreme weather conditions- dense fog during winter and dry dust storms during summer. 


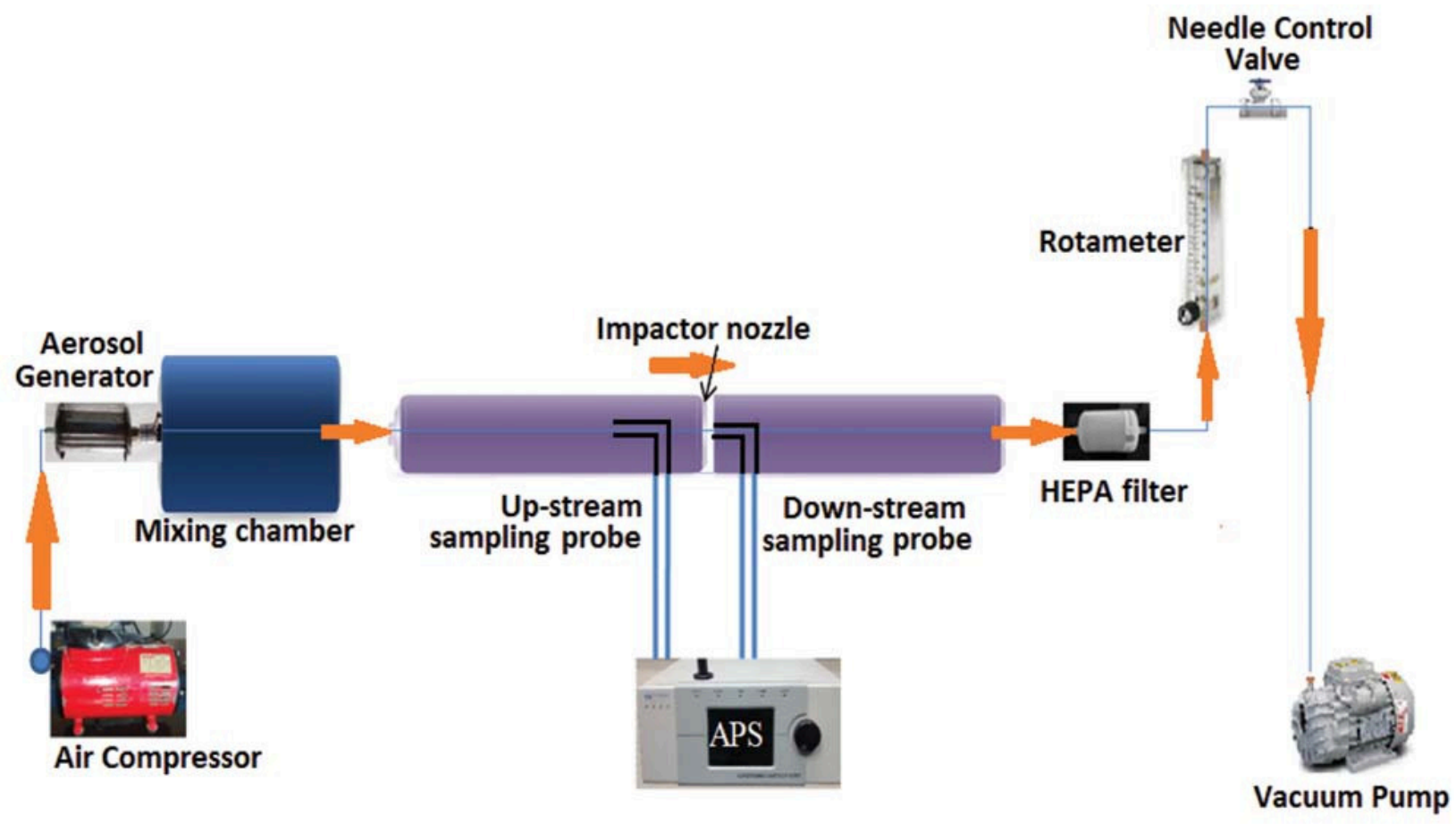

Figure 1. Experimental set-up for characterization of the two impaction stages

\subsection{Aerosol sampling}

Particulate matter sampling was conducted on $47 \mathrm{~mm}$ diameter Whatman ${ }^{\circledR}$ PTFE Membrane filter paper. Pore size of the filter paper was $\leq 0.20 \mu \mathrm{m}$. Filter papers were handled with the help of clean forceps. Each filter paper was preconditioned at $25{ }^{\circ} \mathrm{C}$ and $45 \%-55 \%$ humidity for 12 hours (Chakraborty and Gupta, 2010). Each filter paper was weighed before the sampling and the pre-weight of the filter paper was recorded. The filter paper weighing was carried out on a microbalance (Mettler, Toledo) (Chakraborty and Gupta, 2010). Filter papers were kept in clean custom-made plastic cassettes. All the cassettes were put in a vacuum sealed container. This vacuum sealed container was stored in a refrigerator at $-4{ }^{\circ} \mathrm{C}$ temperature.

$10 \%$ of the filter papers were retained as field blank. For this, every eleventh filter paper was taken out as a blank filter paper. These blank filter papers were also analysed in the same way as the other sampled filter papers.

The same process of weighing the filter papers was repeated after air sampling and the post sampling weights of the filter papers were recorded. Pre-sampling weight of the filter paper was subtracted from post sampling weight of the filter paper so as to calculate $\mathrm{PM}_{0.6}$ mass deposited over it. The same procedure was followed for the field blanks. The mass difference of field blanks were subtracted from the mass difference of sampled filter papers so as to get the net mass of $\mathrm{PM}_{0.6}$ deposited over the filter paper. This was divided by the volume of air sampled through the device so as to obtain airborne concentration of $\mathrm{PM}_{0.6}$. Post sampling, these filter papers were stored as described earlier and were used for further analysis at a later time.

During air sampling campaign, two co-located air sampling devices were used for ambient air sampling. One of the devices was used to collect $\mathrm{PM}_{0.6}$. The other device was used to collect viable bioaerosol samples on different media. The flow rate through the Air Sampling Device was maintained at 12 LPM by the use of vacuum pump, needle control valve and a rotameter. Rotameter was pre-calibrated using a digital mass flow meter. Sampling for $\mathrm{PM}_{06}$ was done for 6 hours and total 4.32 $\mathrm{m}^{3}$ of air was sampled at each location. Air flow rates through the device were checked continuously at an interval of 30 minutes (Gupta and Mandariya, 2013). Sampling for bioaerosol was done for a period of 3 to 4 minutes as decided by experiment described in section 2.2.2.

\subsection{Bioaerosol sampling}

In parallel to $\mathrm{PM}_{0.6}$ sampling, two sets of bioaerosol samplings were performed at the same location. One set was performed at the start of the sampling by the device housing filter paper and another was performed after 5 hours of the start of sampling. Deferring of \pm 15 minutes from the sampling schedule was considered normal. Sampling at each of the microenvironment was repeated after 15 days using the same protocol.

Major steps involved in the bioaerosol sampling were:

i. Disinfection of Air Sampling device and other glassware

ii. Preparation of Sampling Cassettes

iii. Preparation of sampling media (Nutrient agar, Sabouraud Chloramphenicol Agar, MacConkey agar, Mannitol salt agar)

iv. Ambient air sampling at the site

v. Incubation of sampled cassettes

vi. Cell colony-counting and microscopic identification

Before each sampling, air-sampling device was properly cleaned. It was disinfected by using 70\% ethanol, absolute ethanol and methyl alcohol (Merck KGaA, Germany). All the processes were carried out inside a bio-safety cabinet (Biogen Scientific). After this, the sampler and all its components were exposed to U.V. radiations for 20 minutes inside the bio-safety cabinet. All the non-consumable glassware used in bioaerosol sampling and subsequent processes was autoclaved at $15 \mathrm{lbs}$. and $121^{\circ} \mathrm{C}$. $35 \mathrm{~mm}$ - radiation sterile Petri dishes were used as sampling cassettes for bioaerosol sampling. Proper care was taken in preparing culture media as per protocols described in Microbiology Laboratory Manual (Cappuccino, 2005). Previously described culture media were prepared as per the instructions on the label of each media package. Sampling cassettes were prepared by pouring media into Petri dishes in a bio-safety cabinet and allowing the media to solidify by cooling at room temperature.

Bioaerosol sampling was done for 3 or 4 minutes per sample at 12 LPM of airflow. After sampling, the Petri dishes were taken out of the sampler and stored in sterilized transportation cassettes meant for transporting the sampling cassettes to and fro the sampling site and laboratory. All the sampling cassettes were then transferred to the incubator (Esco Technologies, Inc.).

The Petri dishes were kept for incubation at $35^{\circ} \mathrm{C}$ for 24 to $48 \mathrm{~h}$ for incubation of bacterial colonies. For incubation of fungi, the plates were incubated at $35^{\circ} \mathrm{C}$ for 5 days. After cultivation of the plates, the total bacterial and fungal colonies were counted as per the protocol mentioned in microbiology laboratory manual (Cappuccino, 2005). Cell colony counting was done with the help of magnifying glass as per the established methods in Microbiology Laboratory Manual (Cappuccino, 2005). Whole colony appearance of each bacteria colony was recorded as one of the following categories -circular, irregular, biconvex (embedded in agar), filamentous or rhizoid (long projections). Along with this, the margin (entire, undulate, lobate or curled) and elevation (flat, raised, convex or 
umbonate) of the colony were also recorded. An inoculums loop was sterilized until red hot on a Bunsen flame. After cooling, this was used to prepare a smear of colony on a slide by using distilled water. The inoculums from each colony was subjected to negative staining first and then Gram staining as per the protocols described in Microbiology Laboratory Manual (Cappuccino, 2005). Stained bacterial cells were viewed at $4 \mathrm{x}$, 10x, 40x and oil immersion 100x magnification. Slides were viewed with Nikon E 200 upright microscope mounted with a CCD camera make DS-Fi2. The live view and images were analysed with the help of imaging software NIS Elements D from Nikon Instruments Inc

Inoculums from each fungus colony were picked with the help of sterilized and cooled inoculums loop, and placed in cavity of depression slide. Sample was stained with lacto-phenol cotton blue. The stained slide was observed in an inverted microscope (Trinocular Inverted microscope XDS 2, Optika SRL, Italy) with $4 \mathrm{x}, 10 \mathrm{x}, 20 \mathrm{x}$ and $40 \mathrm{x}$ objectives. The live images were viewed with the camera Optika pro 5 and the software Optika Vision Pro 4.3 Pro5. Morphological feature as conidia, conidiophores and hyphae were used for identification of fungal growths in the culture.

Concentration of bioaerosols was reported in terms of the Colony Forming Unit per cubic meter of air in the concerned microenvironment. The equation 5 was used for this purpose.

$$
\text { Colony Forming Units, } C F U / m^{3}=C F U_{\text {Petri }} X(1000 / V)
$$

Here, $V_{s}$ is the total volume of air sampled through the sampling device in the given microenvironment and $\mathrm{CFU}_{\text {Petri }}$ is the number of Colony Forming Units counted in corresponding Petri-dishes.

\section{Developed Air-Sampling Device}

A good air-sampling device is the foremost requirement in sampling studies. The developed air-sampling device and its internal components are shown in figure 2. Brass was used for the fabrication of the developed air-sampling device, due to its advantage in machining, long-term durability, stability and inert characteristics. It was further treated with chrome plating techniques to cover it up with an inert and corrosion-free layer.

The device has three zones. Top of the sampling device is provided with the rain cover.

Zone 1 is for collection of large particles and spores that have settled down due to gravity.

Zone 2 has two stages with cut off points of $\mathrm{PM}_{10}$ and $\mathrm{PM}_{06}$ achieved at an airflow rate of $12 \mathrm{LPM}$. The first stage is $\mathrm{PM}_{10}$ stage. It consists of a nozzle plate containing four round nozzles and one impaction plate. Impaction plate can accommodate four $35 \mathrm{~mm}$ Petri dishes in the respective slots below the nozzles. Second stage is $\mathrm{PM}_{0.6}$ stage. It consists of one nozzle plate with single round nozzle and one corresponding impaction plate. This impaction plate can house one unit $35 \mathrm{~mm}$ Petri dishes.

Zone 3 has provision to house a $47 \mathrm{~mm}$ filter. This zone can collect $\mathrm{PM}_{0.6}$ particulate matter on filter paper that can be subjected to further gravimetric and chemical analysis.

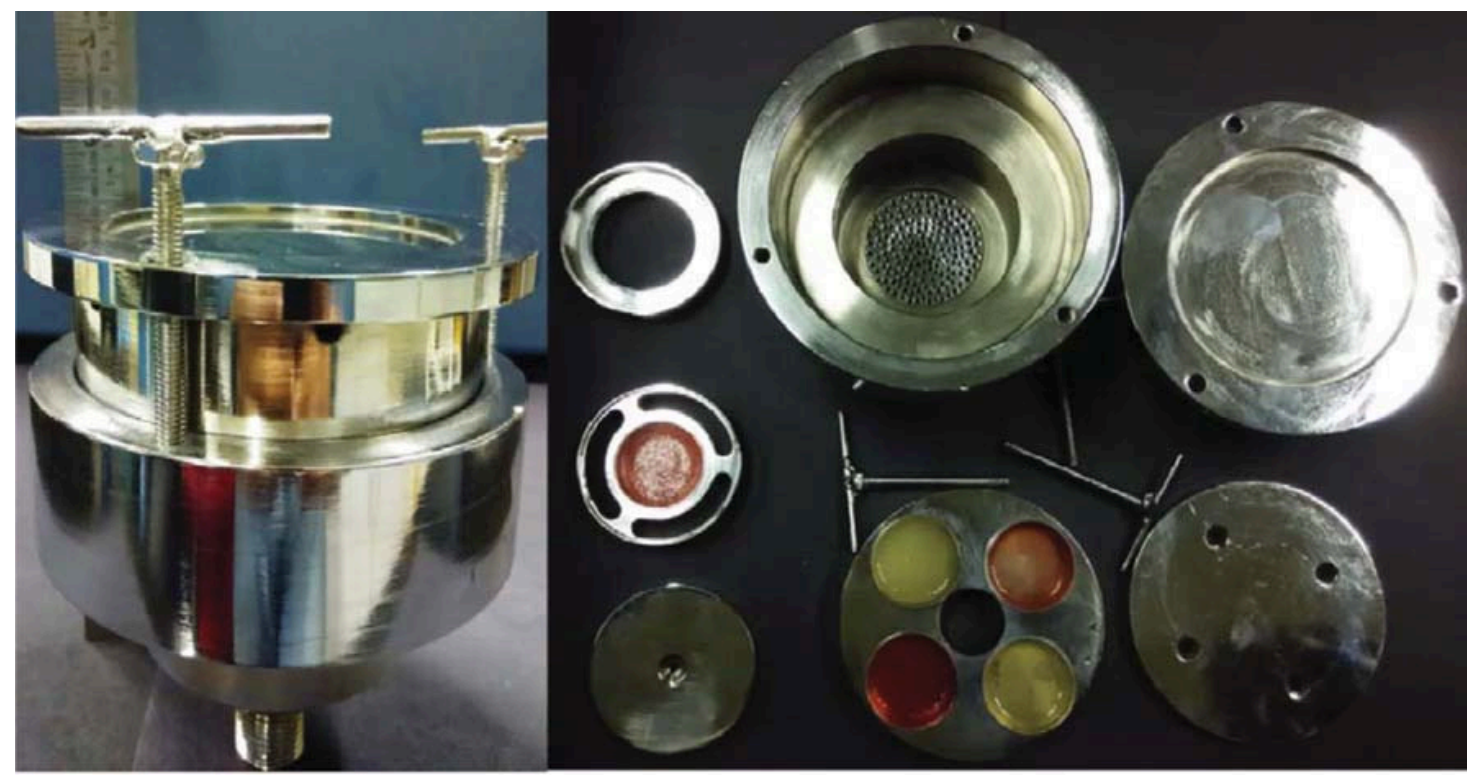

Figure 2 Air Sampling Device and its internal components

Impactor characterization results show that stages 1 and 2 in zone two of the Air Sampling Device have cut off points at $\mathrm{PM}_{10}$ and $\mathrm{PM}_{06}$ respectively (figure 3). PM losses in the nozzle were checked without the use of impaction plates behind the nozzles and it was always found to be below $5 \%$. The sharp cut off points at $0.6 \mu \mathrm{m}$ and $10 \mu \mathrm{m}$ make this device suitable for collecting the particles in the range of $0.6 \mu \mathrm{m}$ and $10 \mu \mathrm{m}$ (table 1).

Impaction plate at first stage collects the particle with size greater than $10 \mu \mathrm{m}$. Particles of size less than $10 \mu \mathrm{m}$ travel down towards the second stage. The impaction plate on the second stage collects the particles of size $0.6 \mu \mathrm{m}$ to $10 \mu \mathrm{m}$.

Next step was to test the performance of this device for collecting bioaerosols. For this, it was desired to find out the optimum duration of air sampling to collect maximum number of bioaerosols on selected nutrient media.

\subsection{Sampling duration for various substrates used for bioaerosol sampling using the developed Air Sampling Device}

The main criteria for selecting the optimum duration was the occurrence of maximum number of colony forming units per cubic meter of sampled air $\left(\mathrm{CFU} / \mathrm{m}^{3}\right)$ with the minimum standard deviation in repeated set of experiments. It was decided that Nutrient agar and Sabouraud Dextrose Agar with Chloramphenicol would be subjected to 3 minutes of sampling per sample. MacConkey agar and Mannitol salt agar were giving best results at 4 minutes of sampling duration. After this time, overcrowding of colonies was observed in the incubated plates and this overlapping of growing colonies inhibits the accurate colony counting

\section{Aerosol profile for IIT Kanpur}

\subsection{PM ${ }_{0.6}$ profile for IITKanpur}

Maximum concentration of $\mathrm{PM}_{06}$ was observed during winter season $\left(204 \pm 56.2 \mu \mathrm{g} / \mathrm{m}^{3}\right)$. Meteorological conditions during winter resulted in settling of the PM near the ground. The concentrations of PM started to decrease with the approach of summer $\left(84.7 \pm 27.8 \mu \mathrm{g} / \mathrm{m}^{3}\right)$. The monsoon rainfall resulted in washing out of the PM from atmosphere and thus the concentration was found to be lowest during the season $(33.01 \pm 9.27 \mu \mathrm{g} /$ $\left.\mathrm{m}^{3}\right)$. Post monsoon the PM concentrations again started to increase in the ambient air $\left(73.7 \pm 2.82 \mu \mathrm{g} / \mathrm{m}^{3}\right)$. The $\mathrm{PM}_{0.6}$ concentrations obtained during the campaign were compared to that with $\mathrm{PM}_{1}$ concentrations ob- 


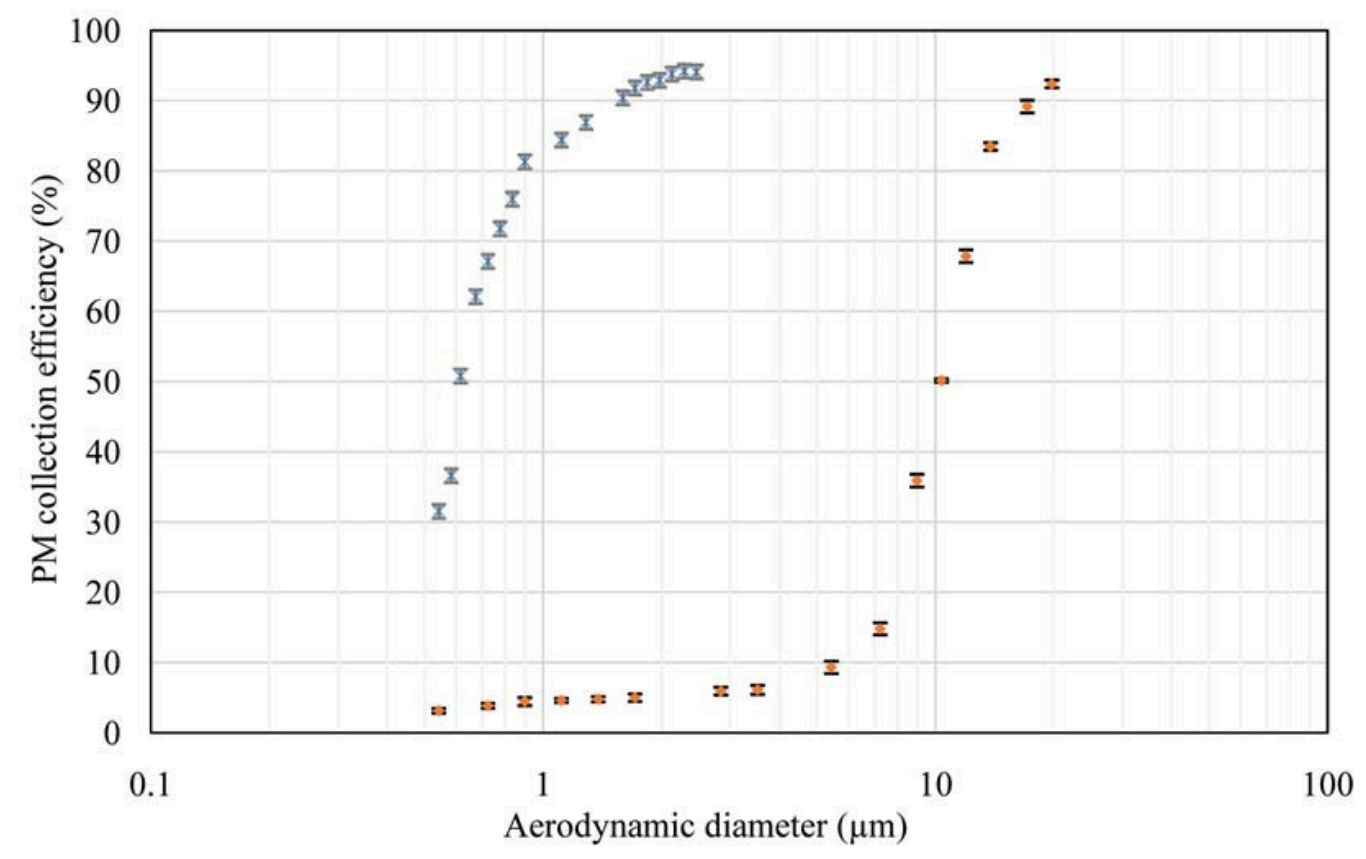

Figure 3a Characterization of stage $\mathrm{I}\left(\mathrm{PM}_{0.6}\right)$ and stage II $\left(\mathrm{PM}_{10}\right)$ impactors

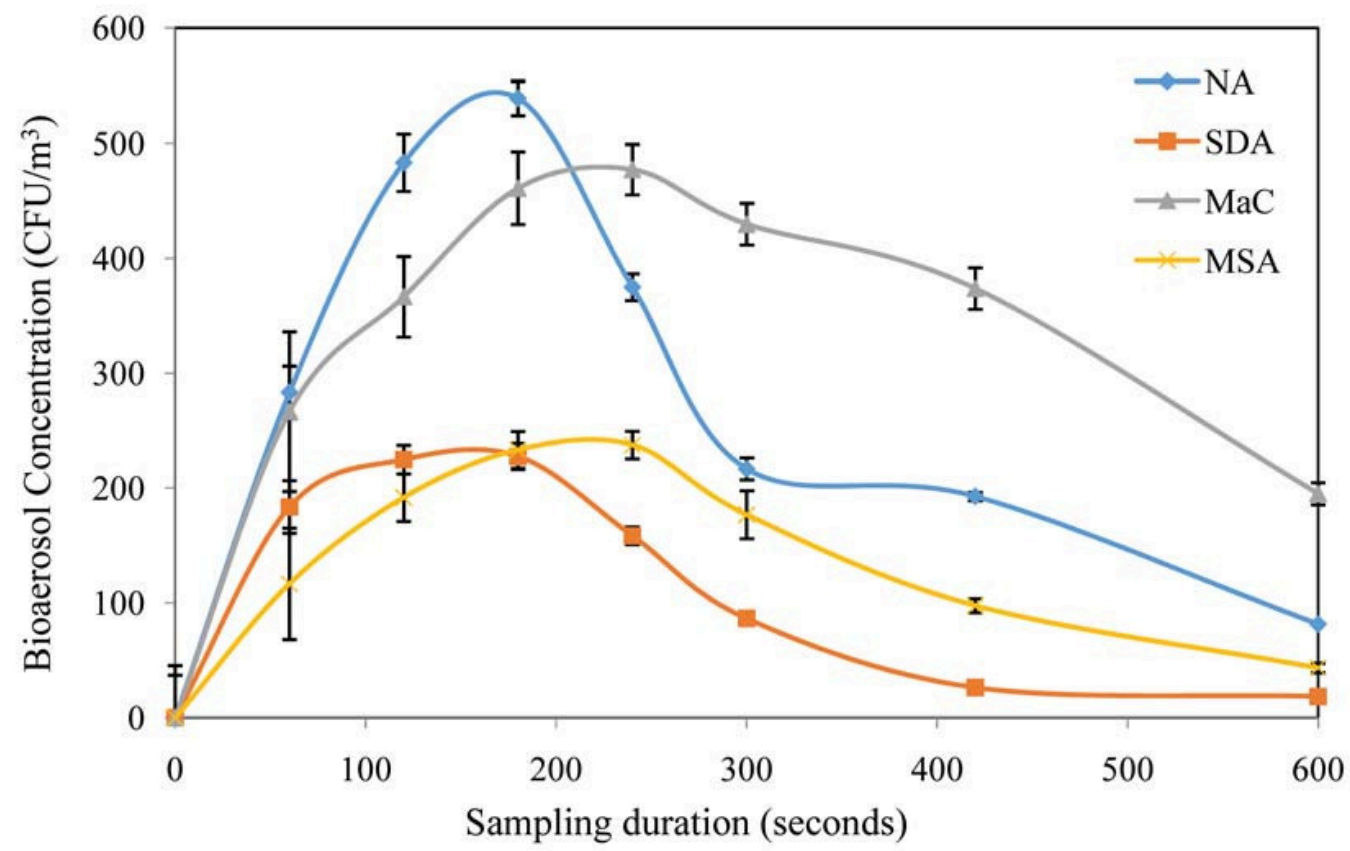

Figure 3b Optimization of the sampling duration for bioaerosol sampling on various impaction substrates used

served at IITK during previous studies (Chakraborty and Gupta, 2010) (table 2). $\mathrm{PM}_{06}$ and $\mathrm{PM}_{1}$ concentrations are almost similar in winter. The pre-summer concentrations of $\mathrm{PM}_{0.6}\left(102.24 \pm 37.97 \mu \mathrm{g} / \mathrm{m}^{3}\right)$ was higher than the $\mathrm{PM}_{1}$ concentration observed during the previous study $(77.1 \pm$ $\left.31.0 \mu \mathrm{g} / \mathrm{m}^{3}\right)$ whereas the $\mathrm{PM}_{06}$ concentration during summer $(84.7 \pm 27.8$ $\mu \mathrm{g} / \mathrm{m}^{3}$ ) was lower than the $\mathrm{PM}_{1}$ concentration observed during previous study $\left(142.3 \pm 45.0 \mu \mathrm{g} / \mathrm{m}^{3}\right)$. The previous study was done at a height of 12 $\mathrm{m}$ from the ground whereas the present study is conducted at a height of only $1.5 \mathrm{~m}$ from the ground. Summer is a season of suspension of dry soil and dust by the wind. Pre summer resulted in the suspension of fine particles that were loosely bound to the surface whereas summer resulted in relatively lesser concentration of fine PM at lower heights due to their escape to higher levels from the ground surface. Similar concentrations for $\mathrm{PM}_{0.95}$ were obtained by another study at IITK during winter. In this study during last decade, the concentrations were found to be $203 \mu \mathrm{g} / \mathrm{m}^{3}$ (Tare et al., 2006). 
Table 1 Characteristics of developed air sampling device

\begin{tabular}{|l|l|}
\hline Parameters & Features \\
\hline No. of Zones & 3 \\
\hline Zone 1 & Settling Zone \\
\hline Flow rate & $12 \mathrm{LPM}$ \\
\hline Zone 2: Stage I & $10 \mu \mathrm{m}$ and above \\
\hline \multicolumn{1}{|c|}{ Number of nozzles } & 4 \\
\hline \multicolumn{1}{|c|}{ Nozzle diameter } & $5 \mathrm{~mm}$ \\
\hline Zone 2: Stage II & $0.6-10 \mu \mathrm{m}$ \\
\hline \multicolumn{1}{|c|}{ Nozzle diameter } & 1 \\
\hline Zone 3 nozzles & $3.2 \mathrm{~mm}$ \\
\hline Height & PM sampling \\
\hline Diameter & 5 inches \\
\hline GSD & 3 inches \\
\hline $\begin{array}{l}\Delta P \text { (Pressure drop) in Impactor with Teflon } \\
\text { paper (47 mm diameter and 0.2 } \mathrm{m} \text { pore size) }\end{array}$ & 1.28 \\
\hline
\end{tabular}

Table 2 Seasonal average $\mathrm{PM}_{0.6}$ and $\mathrm{PM}_{1}$ mass concentration at IIT Kanpur $\left(\mu \mathrm{g} / \mathrm{m}^{3}\right)$

\begin{tabular}{lll}
\hline Season & $\mathrm{PM}_{0.6}$ concentration & $\mathrm{PM}_{1}$ Concentration \\
\hline Winter & $204 \pm 56.2$ & $199.0 \pm 66.0$ \\
Pre Summer & $102.24 \pm 37.97$ & $77.1 \pm 31.0$ \\
Summer & $84.7 \pm 27.8$ & $142.3 \pm 45.0$ \\
Monsoon & $33.01 \pm 9.27$ & $30.1 \pm 13.7$ \\
Post Monsoon & $73.7 \pm 2.82$ & $63.8 \pm 23.7$ \\
\hline
\end{tabular}

\subsection{Bioaerosol profile for IIT Kanpur}

\subsubsection{Indoor bioaerosol profile}

Indoor bioaerosol sampling was done at Environmental Engineering Laboratory at IIT Kanpur. The concentrations of both Gram positive and Gram-negative bacteria were lowest in the month of December. During December, the GPB concentration was $83 \pm 21 \mathrm{CFU} / \mathrm{m}^{3}(\mathrm{n}=6)$ and $\mathrm{GNB}$ concentration was reported as $28 \pm 12 \mathrm{CFU} / \mathrm{m}^{3}(\mathrm{n}=6)$. The concentrations of GPB increased until April $\left(271 \pm 21 \mathrm{CFU} / \mathrm{m}^{3}, \mathrm{n}=6\right)$. The GNB population reached a peak concentration in the month of March $(97 \pm$ $\left.12 \mathrm{CFU} / \mathrm{m}^{3}, \mathrm{n}=6\right)$. This shows that concentrations of both GPB and GNB bacteria were lowest during winter and increased until the onset of summer. With the drastic temperature rise during summer the GPB (167 $\left.\pm 21 \mathrm{CFU} / \mathrm{m}^{3}, \mathrm{n}=6\right)$ and $\mathrm{GNB}$ concentration $\left(63 \pm 20 \mathrm{CFU} / \mathrm{m}^{3}, \mathrm{n}=6\right)$ decreased during the summer months. The onset of monsoon triggered the bacterial growth and the GPB load at WL 116 increased to $373 \pm 18$ $\mathrm{CFU} / \mathrm{m}^{3}(\mathrm{n}=6)$ whereas, GNB load increased to $186 \pm 19 \mathrm{CFU} / \mathrm{m}^{3}$ $(n=6)$ during the month of October. The onset of winter again resulted in the decrease of bacterial concentration from November onwards. The concentration of GNB with respect to GPB was highest during summer end (June) and the onset of monsoon (July). During this period, the actual bioaerosol load was also on the lower side and it was only higher than the bioaerosol load during the winter. During the winter, actual concentrations of GPB $\left(83 \mathrm{CFU} / \mathrm{m}^{3}\right)$ and $\mathrm{GNB}\left(28 \mathrm{CFU} / \mathrm{m}^{3}\right)$ were lowest in the sampling duration and the relative population of GNB was minimum (18\% to $23 \%)$ during the entire sampling duration. This was just opposite to what was observed during the summer where the bioaerosol load was low, but GNB to GPB ratio was highest of the whole year $(30 \%$ to $37 \%$ ) (figure $4 \mathrm{a}$ ).
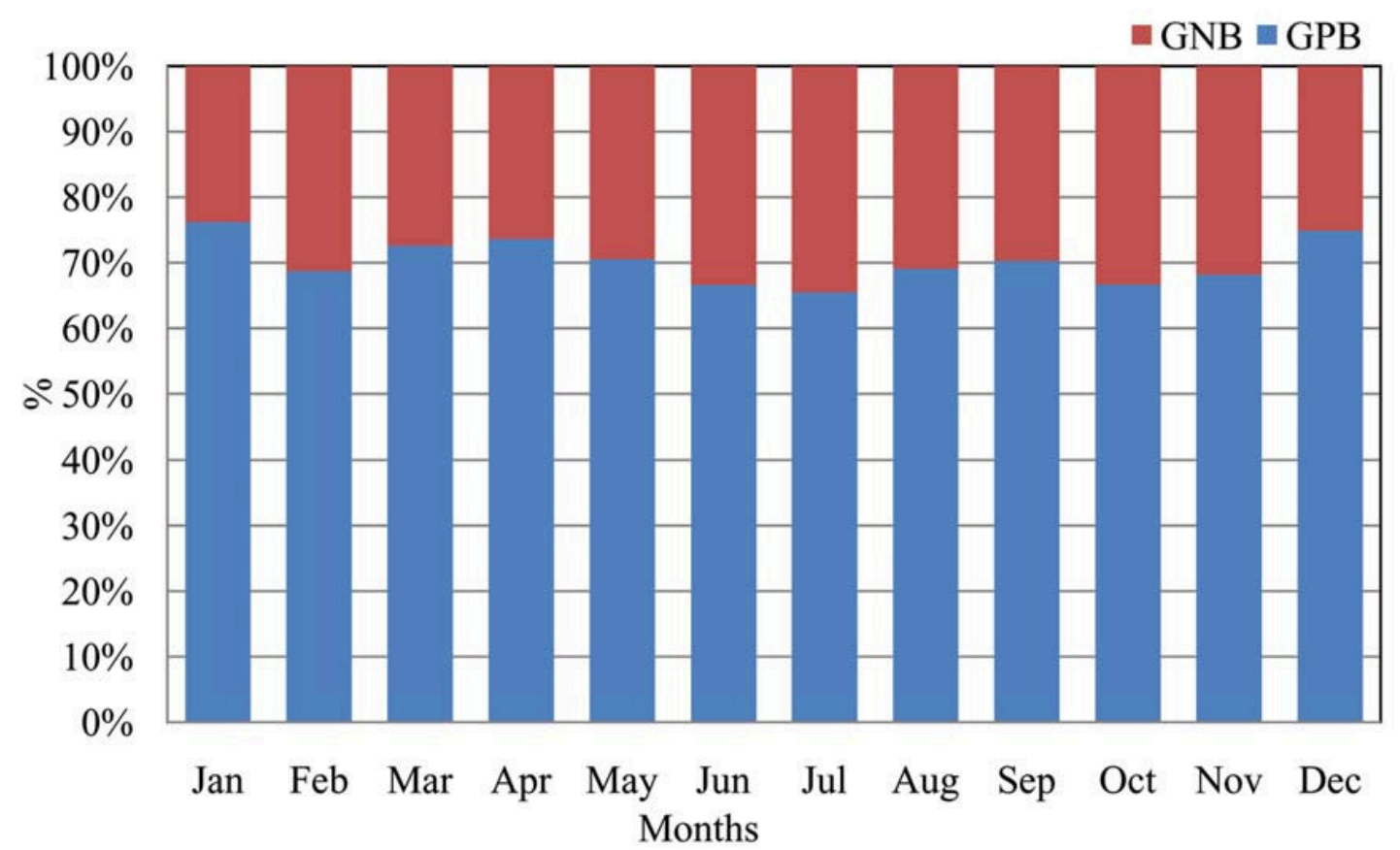

Figure 4a Relative indoor concentrations of GPB and GNB (GPB-Gram Positive Bacteria and GNB-Gram Negative Bacteria)

The maximum concentration of fungi was recorded in the month of September $\left(370 \pm 57 \mathrm{CFU} / \mathrm{m}^{3}, \mathrm{n}=6\right)$ followed by April $(315 \pm 16 \mathrm{CFU} /$ $\left.\mathrm{m}^{3}, \mathrm{n}=6\right)$ and October $\left(306 \pm 28 \mathrm{CFU} / \mathrm{m}^{3}, \mathrm{n}=6\right)$. This shows that maximum fungi concentration was during post monsoon and pre-summer seasons. The concentration of fungi in the ambient air decreased with the onset of winter and summer and the concentration was minimum during the months of July $\left(111 \pm 0 \mathrm{CFU} / \mathrm{m}^{3}, \mathrm{n}=6\right)$ followed by that in January $\left(148 \pm 16 \mathrm{CFU} / \mathrm{m}^{3}, \mathrm{n}=6\right)$. The total bioaerosol load in the ambient air of WL 116 was highest $\left(884 \mathrm{CFU} / \mathrm{m}^{3}, \mathrm{n}=6\right)$ during the post-monsoon season and was minimum $\left(278 \mathrm{CFU} / \mathrm{m}^{3}, \mathrm{n}=6\right)$ during the winter season. September $\left(884 \mathrm{CFU} / \mathrm{m}^{3}, \mathrm{n}=6\right)$ and October $\left(865 \mathrm{CFU} / \mathrm{m}^{3}, \mathrm{n}=6\right)$ had maximum bioaerosol levels followed by March $\left(613 \mathrm{CFU} / \mathrm{m}^{3}, \mathrm{n}=6\right)$ and April $\left(683 \mathrm{CFU} / \mathrm{m}^{3}, \mathrm{n}=6\right)$. The months of December $\left(278 \mathrm{CFU} / \mathrm{m}^{3}\right.$, $\mathrm{n}=6)$, January $\left(294 \mathrm{CFU} / \mathrm{m}^{3}, \mathrm{n}=6\right)$ and July $\left(313 \mathrm{CFU} / \mathrm{m}^{3}, \mathrm{n}=6\right)$ had a lowest bioaerosol load in the indoor ambient air at WL 116. It is important to note that despite similar total bioaerosol load, the composition of bioaerosols was quite different during those months. 


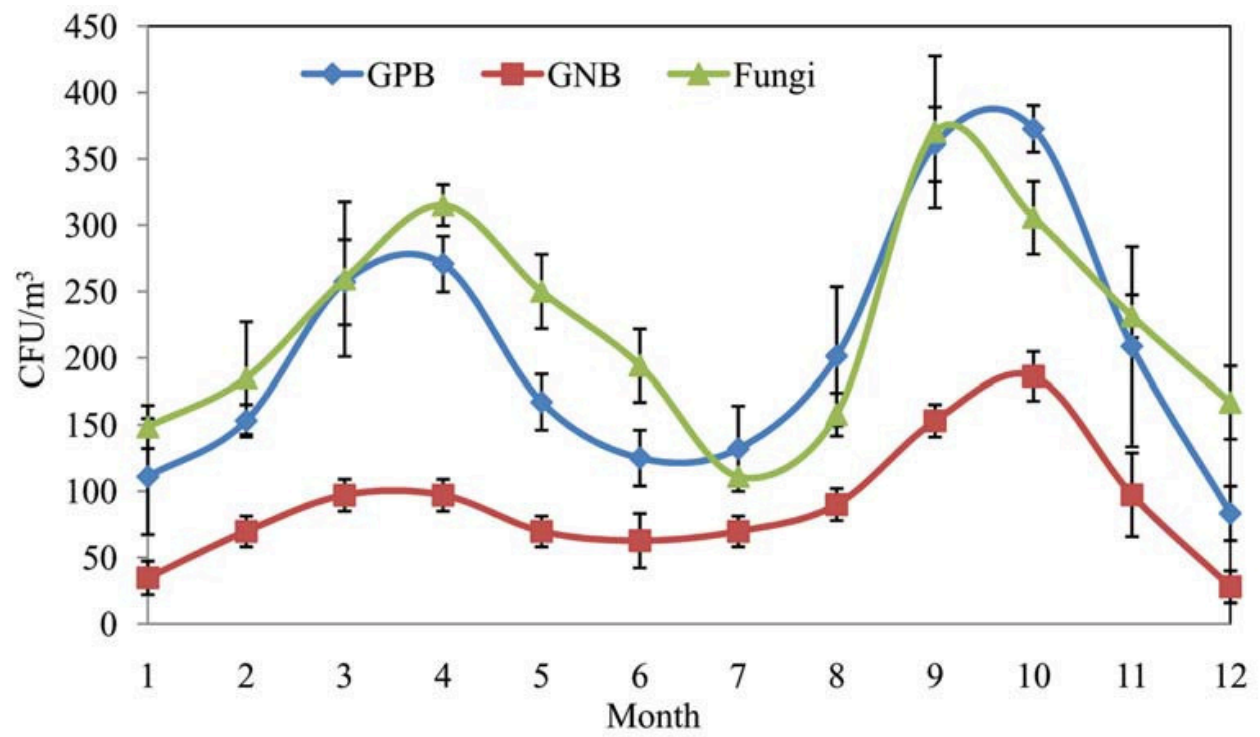

Figure 4b Indoor bioaerosol profile (GPB-Gram Positive Bacteria, GNB-Gram Negative Bacteria and Fungi)

\subsubsection{Outdoor bioaerosol profile}

Outdoor bioaerosol sampling was done in backyard of Environmental Engineering laboratory. The lowest concentration of GPB was observed during the winter with concentrations of $\left(70 \pm 12 \mathrm{CFU} / \mathrm{m}^{3}, \mathrm{n}=6\right)$ during January and $\left(70 \pm 12 \mathrm{CFU} / \mathrm{m}^{3}, \mathrm{n}=6\right)$ during December. The lowest concentration for GNB was observed in the month of December (14 \pm 12 $\left.\mathrm{CFU} / \mathrm{m}^{3}, \mathrm{n}=6\right)$. Outdoor GPB concentration increased until early summer (April- $264 \pm 12 \mathrm{CFU} / \mathrm{m}^{3}, \mathrm{n}=6$ and May, $264 \pm 32 \mathrm{CFU} / \mathrm{m}^{3}$, $\mathrm{n}=6$ ). Although the concentration of GPB in May was equal to that in April, the standard deviation was slightly higher in May. This was due to a sharp decline in GPB concentration during early May $\left(292 \mathrm{CFU} / \mathrm{m}^{3}\right)$ to $229 \mathrm{CFU} / \mathrm{m}^{3}$ during late May. This decline in concentration continued until early monsoon (July $132 \pm 32 \mathrm{CFU} / \mathrm{m}^{3}, \mathrm{n}=6$ ). GPB concentration started to increase with the onset of monsoon reaching a maximum concentration of $\left(299 \pm 12 \mathrm{CFU} / \mathrm{m}^{3}, \mathrm{n}=6\right)$ during late September and early October. With the onset of winter, decrease in temperature lead to a decrease in GPB concentration reaching a minimum during December. Concentration of GNB was minimum during the winter (December $21 \pm$ $21 \mathrm{CFU} / \mathrm{m}^{3}, \mathrm{n}=6$ and January, $\left.14 \pm 12 \mathrm{CFU} / \mathrm{m}^{3}, \mathrm{n}=6\right)$. Favourable conditions with tree sheds, gardening and other anthropogenic activities; and absence of direct hot winds lead to the increase in concentration of
GNB after winter until May $\left(111 \pm 12 \mathrm{CFU} / \mathrm{m}^{3}, \mathrm{n}=6\right)$. After this there was a decline in GNB concentration due to the intense summer (July- 49 $\left.\pm 12 \mathrm{CFU} / \mathrm{m}^{3}, \mathrm{n}=6\right)$. The concentration of GNB started to increase with the monsoon season and the favourable conditions resulted in a higher value of $132 \pm 24 \mathrm{CFU} / \mathrm{m}^{3}(\mathrm{n}=6)$ during October.

Although, June was the month of low bacterial load, the percentage of GNB was maximum (37\%) during this month. This might be because of watering, gardening, manure applications and environmental engineering laboratory related activities at backyard. Similar results were observed in the month of October (36\%) when the GNB concentration was maximum during the year. GNB vs. GPB ratio was lowest during the winter (and early pre-summer) as GPB population increased rapidly during this period as compared to GNB at backyard during these months (figure 5a).

The outdoor fungi concentration was low as compared to indoor microenvironment of Environmental Engineering Laboratory. This suggests towards the presence of indoor fungal sources at WL116. Further, the fungi concentration in September $\left(306 \pm 28 \mathrm{CFU} / \mathrm{m}^{3}, \mathrm{n}=6\right)$ is higher than GPB concentration $\left(292 \pm 21 \mathrm{CFU} / \mathrm{m}^{3}, \mathrm{n}=6\right)$ at backyard. The fungi concentration at backyard was higher than GPB from the onset of monsoon and until winter. This might be due to fungal growth on trees, woody scrap materials, gardening practices and other materials lying there.

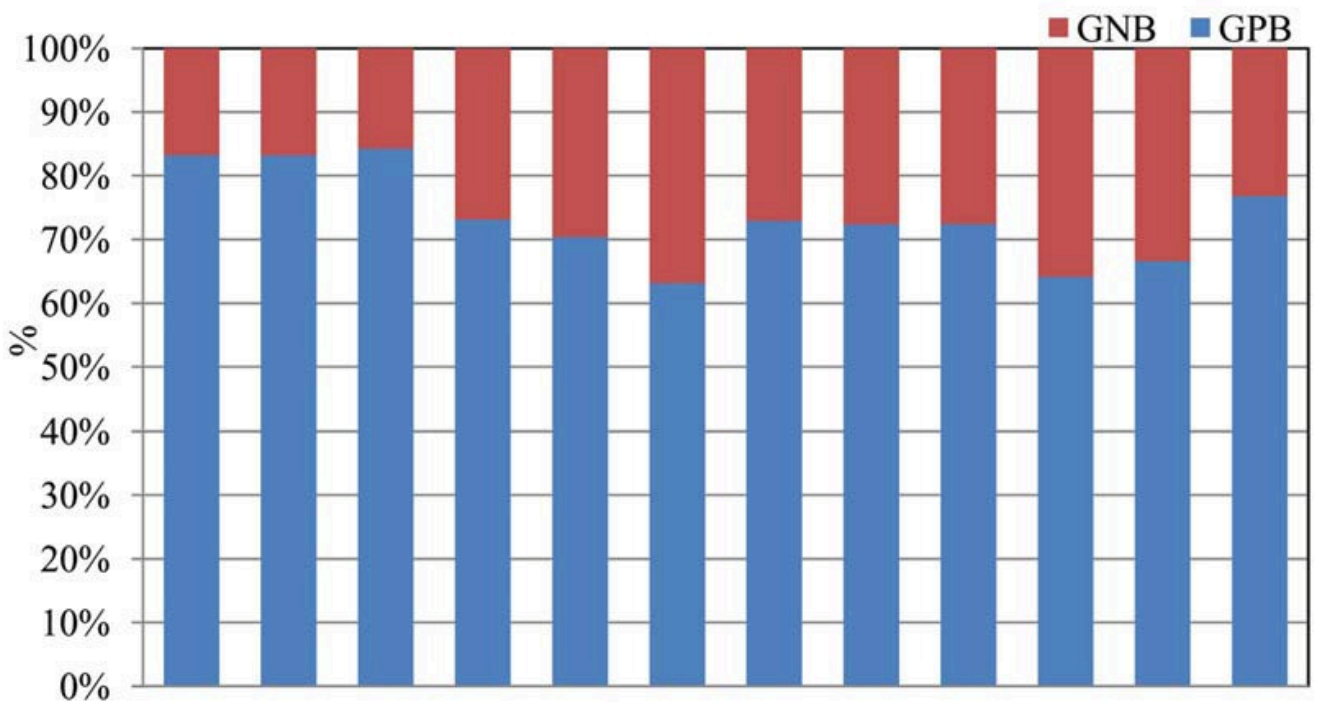

Jan Feb Mar Apr May Jun Jul Aug Sep Oct Nov Dec

Figure 5a Relative outdoor concentrations of GPB and GNB (GPB-Gram Positive Bacteria and GNB-Gram Negative Bacteria) 


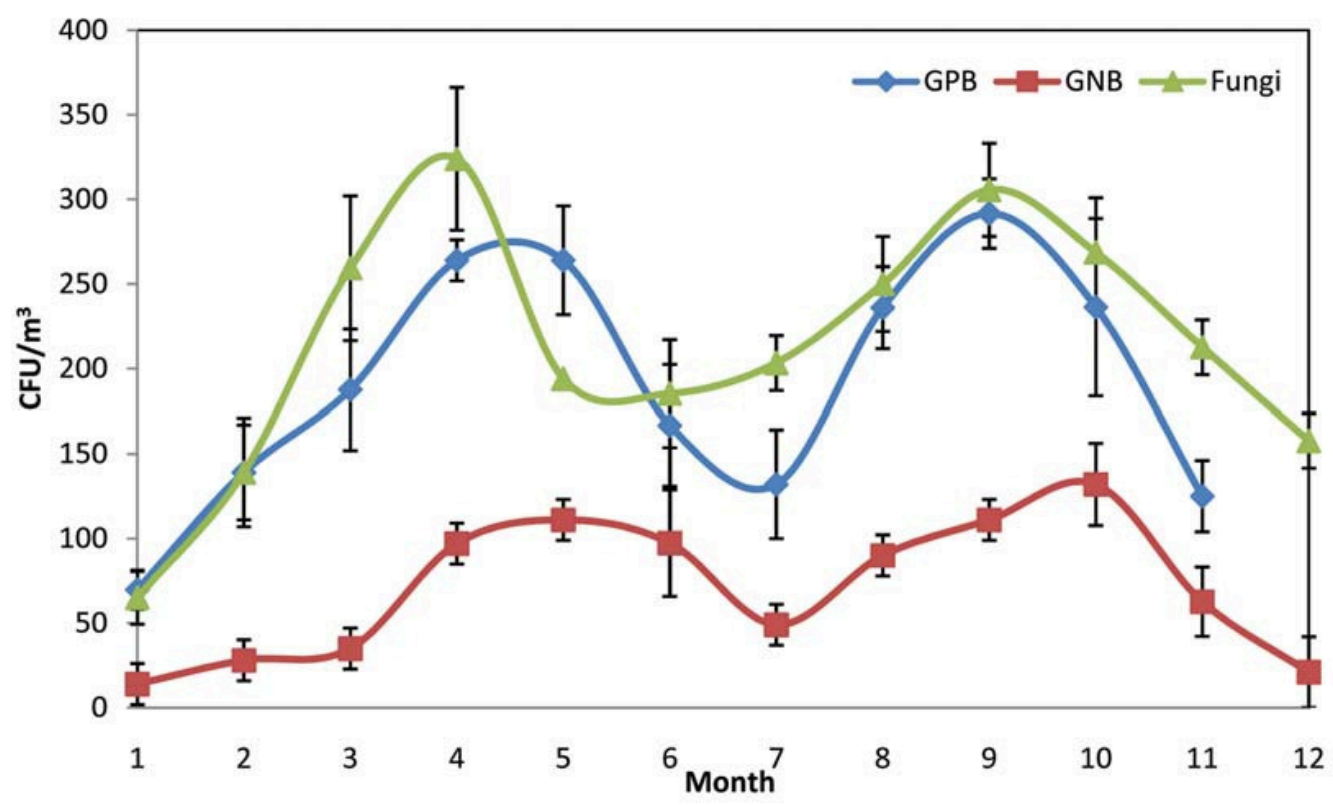

Figure 5b Outdoor bioaerosol profile

(GPB-Gram Positive Bacteria, GNB-Gram Negative Bacteria and Fungi)

The total outdoor bioaerosol load at Environmental Engineering Laboratory backyard shows that despite the varying composition, the bioaerosol load was maximum in the month of September (708 CFU/ $\left.\mathrm{m}^{3}\right)$ and April $\left(685 \mathrm{CFU} / \mathrm{m}^{3}\right)$ and winter has minimum bioaerosol load (Jan, $149 \mathrm{CFU} / \mathrm{m}^{3}$ and Dec $248 \mathrm{CFU} / \mathrm{m}^{3}$ ) (figure $5 \mathrm{~b}$ ).

\subsubsection{Bioaerosol based indoor air quality assessment}

Ratio of indoor bioaerosol concentrations to that of outdoor bioaerosol concentrations was calculated to assess the indoor air quality during the study period (figure 6). Values above 1 indicate towards the indoor source of concerned bioaerosol in the ambient air. The controlled indoor microenvironment provides ample habitat for bioaerosols. The controlled temperature and thus humidity allows bioaerosols to flourish indoor. A low indoor bioaerosol concentration as compared to outdoor concentration suggests that indoor has a cleaner and safe microenvironment. However an opposite trend suggests that bioaerosols source is present indoor. Extreme environmental conditions may lead to elimination of such sources. The figure shows that GPB source was persistent throughout the year at Environmental Engineering Laboratory except for the month of May, June and August. The high ratio for GNB during January, February and March depicts the presence of rich source of GNB in the indoor environment. This source was persistent except for the peak summer months of May and June. Similarly, the indoor source of fungi was evident in the post monsoon season and continued to survive until the pre-summer period.

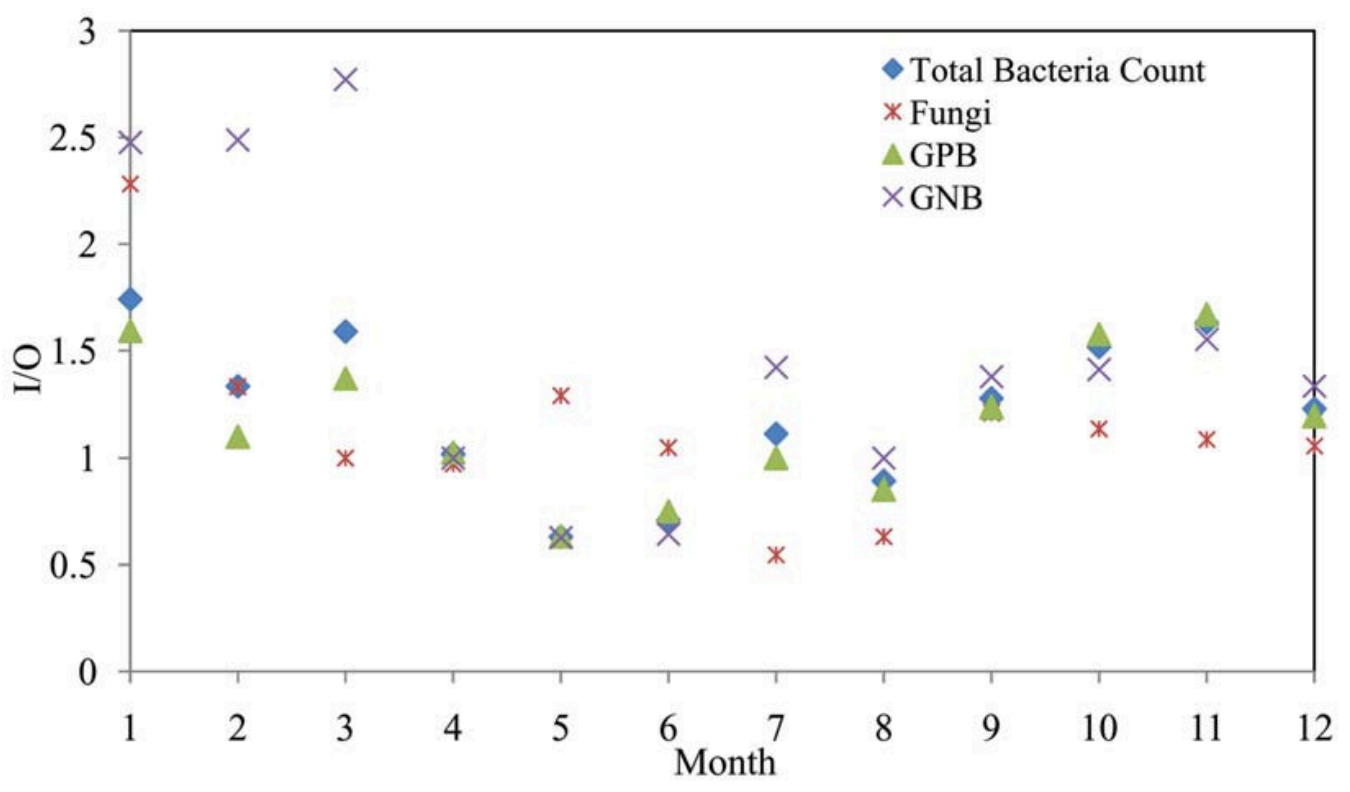

Figure 6 Bioaerosol based indoor Air-Quality

(GPB-Gram Positive Bacteria, GNB-Gram Negative Bacteria and Fungi) 
Very few studies on the bioaerosol concentrations in the ambient air are available from central India. One of such study about the concentration of Fungi in a library and a bakery at Gwalior city situated in central India is done using an Andersen two-stage sampler. The authors used Sabouraud Agar Media for measuring the fungi concentration in the ambient air. Indoor concentration of $<300 \mathrm{CFU} / \mathrm{m}^{3}$ was obtained in the library and $>200 \mathrm{CFU} / \mathrm{m}^{3}$ was obtained in the bakery (Jain, 2000). In one of the rare study on bioaerosols done in Indo-Gangetic region, the authors reported the bioaerosol concentration at Agra $\left(27^{\circ} 102 \mathrm{~N}, 78^{\circ} 052 \mathrm{E}\right)$. In this study, researchers used Sabouraud dextrose agar media for fungi and nutrient agar media for bacteria sample collection. They reported total microbial count in the range of $125 \mathrm{CFU} / \mathrm{m}^{3}$ to $725 \mathrm{CFU} / \mathrm{m}^{3}$. Total bacteria concentration and fungi concentration in $\mathrm{PM}_{10}$ sampling during the study was 72.5 to $625 \mathrm{CFU} / \mathrm{m}^{3}$, and 62.5 to $104.2 \mathrm{CFU} / \mathrm{m}^{3}$ respectively (Mamta et al., 2015).

\section{Summary}

Ambient air quality has direct as well as indirect effect on health of living organism as well as environment. There is a need to understand various biological as well as non-biological components present in the ambient air. For a developing nation like India, availability of inexpensive multi purpose air sampling device can help in saving money and also in serving science and society. Present study fulfils the need for such sampler. The developed sampler can be used for $\mathrm{PM}_{0.6}, \mathrm{PM}_{10}$ and bioaerosol sampling.

The results of samples from developed sampler for $\mathrm{PM}_{0.6}$ correlate well with those obtained during previous studies at IIT Kanpur. Bioaerosol concentrations of the samples collected from this sampler were also in comparable range as obtained in previous studies done in Central India and Indo-Gangetic Plain (IGP) region. Further, this is the first of its kind of study that reports bioaerosol profile for IGP region. This study also reports for the $\mathrm{PM}_{0.6}$ and bioaerosol profile at breathing zone of individuals. This study presents bioaerosol as well as $\mathrm{PM}_{0.6}$ inventory and seasonal trends for a relatively clean academic campussituated within a highly polluted city in IGP.

\section{References}

Baron, P.A. and Willeke, K. (2001) Aerosol measurement: principles, techniques, and applications, Wiley.

Brunekreef, B. and Holgate, S.T. (2002) Air pollution and health., Lancet, 360, 1233-42

James G. Cappuccino (2005) Microbiology: A Laboratory Manual, 7/e, Pearson Education.

Castellani Pastoris, M., Ciceroni, L., Lo Monaco, R., Goldoni, P., Mentore, B., Flego, G., Cattani, L., Ciarrocchi, S., Pinto, A and Visca, P. (1997) Molecular epidemiology of an outbreak of Legionnaires' disease associated with a cooling tower in GenovaSestri Ponente, Italy., Eur. J. Clin. Microbiol. Infect. Dis., 16, 883-92.

Chakraborty, A. and Gupta, T. (2010) Chemical Characterization and Source Apportionment of Submicron $\left(\mathrm{PM}_{1}\right)$ Aerosol in Kanpur Region, India, Aerosol Air Qual. Res., 10, $433-445$

Demokritou, P., Kavouras, I.G., Ferguson, S.T. and Koutrakis, P. (2001) Development and Laboratory Performance Evaluation of a Personal Multipollutant Sampler for Simultaneous Measurements of Particulate and Gaseous Pollutants, Aerosol Sci. Technol., 35, 741-752.

Demokritou, P., Gupta, T., Ferguson, S. and Koutrakis, P. (2002) Development and Laboratory Performance Evaluation of a Personal Cascade Impactor, J. Air Waste Manage. Assoc., Taylor \& Francis, 52, 1230-1237.

Douwes, J. (2003) Bioaerosol Health Effects and Exposure Assessment: Progress and Prospects, Ann. Occup. Hyg., 47, 187-200.

Evans, J., Tosteson, T. and Kinney, P. (1984) Cross-sectional mortality studies and air pollution risk assessment, Environ. Int., 10, 55-83.

Fernandez, R.C. (2012) Airborne transmission of Bordetella pertussis demonstrated in a baboon model of whooping cough, J. Infect. Dis., 206, 808-10.

Ghosh, S., Gupta, T., Rastogi, N., Gaur, A., Misra, A., Tripathi, S.N., Paul, D., Tare, V., Prakash, O., Bhattu, D., Dwivedi, A.K., S.Kaul, D., Dalai, R. and Mishra, S.K.
(2014) Chemical Characterization of Summertime Dust Events at Kanpur: Insight into the Sources and Level of Mixing with Anthropogenic Emissions, Aerosol Air Qual. Res., 14, 879-891.

Gupta, T. and Mandariya, A. (2013) Sources of submicron aerosol during fog-dominated wintertime at Kanpur, Environ. Sci. Pollut. Res. Int., 20, 5615-29.

Gupta, T., Demokritou, P. and Koutrakis, P. (2004) Development and Performance Evaluation of a High-Volume Ultrafine Particle Concentrator for Inhalation Toxicological Studies, Informa UK Ltd UK, 16, 851-862.

Gupta, T., Jaiprakash and Dubey, S. (2011) Field performance evaluation of a newly developed $\mathrm{PM}_{2,5}$ sampler at IIT Kanpur, Sci. Total Environ., 409, 3500-7.

Hall, J. V. (1996) Assessing health effects of air pollution, Atmos. Environ., 30, 743-746

Harrison, R.M. and Yin, J. (2000) Particulate matter in the atmosphere: which particle properties are important for its effects on health?, Sci. Total Environ., 249, 85-101.

Hinds, W.C. (1982) Aerosol technology: properties, behavior, and measurement of airborne particles, Wiley-Interscience,New York, NY

Jain, A.K. (2000) Survey of bioaerosol in different indoor working environments in central India, Aerobiologia (Bologna)., Kluwer Academic Publishers, 16, 221-225.

Järup, L. (2003) Hazards of heavy metal contamination, Br. Med. Bull., 68, 167-182

Kampa, M. and Castanas, E. (2008) Human health effects of air pollution, Environ. Pollut., $151,362-7$.

Kumar, A. and Gupta, T. (2015) Development and Field Evaluation of a Multiple Slit Nozzle-Based High Volume PM2.5 Inertial Impactor Assembly (HVIA), Aerosol Air Qual. Res., 15, 1-13.

Kuo, C.Y. Wong, R.H. Lin, J.Y. Lai, J.C. and Lee, H. (2006) Accumulation of chromium and nickel metals in lung tumors from lung cancer patients in Taiwan, J. Toxicol. Environ. Health. A, 69, 1337-44.

Macher, J.M. and Macher, J.M. (1997) Evaluation of Bioaerosol Sampler Performance, Appl. Occup. Environ. Hyg., 12, 730-736.

Mamta. Shrivastava, J. N. Satsangi, G.P. and Kumar, R. (2015) Assessment of bioaerosol pollution over Indo-Gangetic plain, Environ. Sci. Pollut. Res., 22, 6004-6009.

Marple, V.A. and Liu, B.Y.H. (1974) Characteristics of laminar jet impactors, Environ. Sci. Technol., American Chemical Society, 8, 648-654

Marple, V. A. (2004) History of Impactors-The First 110 Years, Aerosol Science and Technology, 38, 247-292

Marple, V. A. and Willeke, K. (1976) Impactor design, Atmos. Environ., 10, 891-896.

Mcfarland, A.R., Ortiz, C.A. and Bertch, R.W.J. (1978) Particle Collection Characteristics of a Single-Stage Dichotomous Sampler, Environ. Sience Technol., 12, 679-682.

Nawrot, T. Plusquin, M. Hogervorst, J. Roels, H. A. Celis, H. Thijs, L. Vangronsveld, J. Van Hecke, E. and Staessen, J. A (2006) Environmental exposure to cadmium and risk of cancer: a prospective population-based study, Lancet Oncol., 7, 119-26.

Nazaroff, W.W. (2016) Indoor bioaerosol dynamics, Indoor Air, 26, 61-78.

Özkaynak, H. and Thurston, G.D. (1987) Associations Between 1980 U.S. Mortality Rates and Alternative Measures of Airborne Particle Concentration, Risk Anal., Blackwell Publishing Ltd, 7, 449-461.

Riediker, M. Cascio, W.E. Griggs, T.R. Herbst, M.C. Bromberg, P. A. Neas, L. Williams, R.W. and Devlin, R.B. (2004) Particulate matter exposure in cars is associated with cardiovascular effects in healthy young men, Am. J. Respir. Crit. Care Med., 169, 934-40

Sharma, M. and Maloo, S. (2005) Assessment of ambient air PM and PM and characterization of PM in the city of Kanpur, India, Atmos. Environ., 39, 60156026 .

Singh, S. Sapra, B.K. Khan, A. Kothalkar, P.K. and Mayya, Y.S. (2010) Development of a variable configuration cascade impactor for aerosol size distribution measurement, Atmos. Environ., Elsevier Ltd, 44, 795-802.

Tare, V. Tripathi, S.N. Chinnam, N. Srivastava, A.K. Dey, S. Manar, M. Kanawade, V.P Agarwal, A. Kishore, S. Lal, R.B. and Sharma, M. (2006) Measurements of atmospheric parameters during Indian Space Research Organization Geosphere Biosphere Program Land Campaign II at a typical location in the Ganga Basin: 2. Chemical properties, J. Geophys. Res., 111, D23210.

Tripathi, S. N. Tare, V. Chinnam, N. Srivastava, A. K. Dey, S. Agarwal, A. Kishore, S. Lal, R. B. Manar, M. Kanwade, V.P. Chauhan, S.S. S. Sharma, M. Reddy, R. R. Gopal, K R. Narasimhulu, K. Reddy, L.S. S. Gupta, S. and Lal, S. (2006) Measurements of atmospheric parameters during Indian Space Research Organization Geosphere Biosphere Programme Land Campaign II at a typical location in the Ganga basin: 1. Physical and optical properties, J. Geophys. Res., 111, D23209.

Vermylen, J. Nemmar, A. Nemery, B. and Hoylaerts, M.F. (2005) Ambient air pollution and acute myocardial infarction, J. Thromb. Haemost., 3, 1955-61. 